\title{
O Trabalho do Profissional de Saúde Mental em um Processo de Desinstitucionalização
}

| ${ }^{1}$ Carlos Eduardo de Moraes Honorato, ${ }^{2}$ Roseni Pinheiro |

Resumo: O artigo apresenta um recorte da pesquisa realizada em 2006 sobre o trabalho dos profissionais de saúde mental responsáveis pelo acompanhamento a moradores dos serviços residenciais terapêuticos do município de Carmo, no Estado do Rio de Janeiro. Estas moradias constituem uma etapa do processo de desinstitucionalização de um hospital psiquiátrico estadual do tipo colônia agrí́cola, fundado na década de 1940, onde estavam internados cerca de 280 pacientes. A partir de 2003, com a extinção do hospital, coordenada pelo gestor estadual, e a municipalização dos recursos, uma pequena parcela dos internos retornou ao seio familiar, mas a maioria (153) foi alocada em moradias assistidas, espalhadas pelas áreas urbana e rural do município. Tomando a tarefa de reinserção social como parte do viés político da Reforma Psiquiátrica brasileira, o trabalho cotidiano da equipe multiprofissional é focalizado. Neste plano relacional do trabalho, utilizamos a abordagem ergológica como arcabouço conceitual para a análise dos processos de trabalho. Iremos nos deter na discussão do trabalho junto à sociedade civil, em que o investimento dos técnicos visa a mudança do estatuto social do louco. No cotidiano, a experiência dos técnicos envolvidos mais diretamente com os moradores, como os cuidadores, produz uma "técnica" de escuta e mobilização, que não admite cartilhas nem regras preestabelecidas ou imutáveis.

> Palavras-chave: Desinstitucionalização; serviços residenciais terapêuticos; trabalho político; integralidade; Reforma Psiquiátrica.
${ }^{1}$ Médico psiquiatra da Assessoria de Saúde Mental da SESDEC-RJ, mestre em Saúde Coletiva pelo IMS-UERJ. Endereço eletrônico:

caduhonorato@uol.com.br.

2 Enfermeira, doutora em Saúde Coletiva pelo IMS-UERJ, professora adjunta, IMS-UERJ. Endereço eletrônico: rosenisaude@uol.com.br. 


\section{Introdução}

Este artigo tem como objetivo refletir sobre o trabalho em equipe dos profissionais de saúde mental responsáveis pelos serviços residenciais terapêuticos, e a forma como se organizam para gerir sua ação específica. Entendemos que o trabalho em saúde mental, formulado segundo os princípios da Reforma Psiquiátrica brasileira, se constitui como uma ação inclusiva, e se coloca para além de qualquer especificidade técnica do profissional envolvido. Trata-se de uma tarefa descrita explicitamente como social (BRASIL, 2006), que só pode ser realizada conjuntamente.

Considerar o louco em sua relação com a cultura e a sociedade implica ampliar o ângulo de visão do homem, percebendo as limitações de qualquer ação individual e nos impulsionando a buscar a participação de outros atores. Entender e intervir na dinâmica das relações do louco com a família, com a comunidade, com a justiça ou com a saúde é trabalho para muitos, trabalho para uma equipe.

Hannah Arendt nos ajuda a pensá-lo como trabalho político. Arendt (1991, 2004) resgata o conceito de política em seu sentido grego original, relativo à polis, conforme descrita na Política, de Aristóteles: nas palavras de Bobbio (2004), cidade de caráter independente ou auto-suficiente, ordenada à base de uma constituição. Tratava-se de um espaço determinado espacialmente, onde, livre tanto das formas de coação como das obrigações da casa (da família), o homem usufruía do direito à atividade política, onde, entre iguais, "regulamentavam todos os assuntos por meio da conversa mútua e do convencimento recíproco" (ARENDT, 2004, p. 48).

Para se viver na polis, portanto, era preciso libertar-se das necessidades da vida, de tudo o que submete. Arendt fala então de um espaço público, onde as pessoas possam ver e ser vistas, falar e ser ouvidas, e onde, iguais entre si, todos dispõem sobre os assuntos do bem comum.

$\mathrm{O}$ conceito de política refere-se, assim, à multiplicidade, à diversidade, àquilo que emerge da convivência dos homens entre si. Pois só é possível conhecer o mundo como algo comum a muitos. Nesta convivência, as coisas se dão através de opinião (doxa), discussão, julgamento e avaliação, conflitos, embates, negociações, argumentaçôes. No espaço público, o discurso produz ação. Na pesquisa que realizamos, e que sustenta o presente artigo, eram essas interações que nos interessavam ${ }^{1}$.

Já Antonio Gramsci nos mostra que estes debates, esta política que se dá na sociedade civil gera ideologia, poder e transformação. Gramsci (2004) ressalta o 
papel da cultura na formação da hegemonia, a relação entre pensamento e ação (práxis). Acredita, portanto, que seja possível uma mudança nas mentalidades, e que isto também determina o poder dominante. $\mathrm{O}$ que, pensamos, atesta a legitimidade da tarefa política da Reforma Psiquiátrica brasileira. Gramsci destaca ainda a função do intelectual como educador, persuasor permanente, formador para o processo de construção da hegemonia. Isto nos permite caracterizar o trabalho do profissional de saúde mental como prática política, práxis que tem a transformação social como objetivo. Tomamos então a proposta de mudança para uma nova forma hegemônica de pensar o louco como tarefa da Reforma Psiquiátrica brasileira.

Utilizaremos as propostas das disciplinas ergonômica e ergológica (SCHWARTZ, 1997, 1998, 2004 e 2006; MUNIZ, 2006; TELLES; ALVAREZ, 2004; BRITO, 2004), percebendo a análise do trabalho como reveladora de um processo criador no qual, a partir da tarefa proposta, as atividades resultam. Orientadas por éticas, resultam de interações, desdobrando um conhecimento técnico, e o rol das experiências. E só resultam por existirem em um mundo social, um mundo coletivo. Selecionamos, portanto, a abordagem ergológica, por oferecer uma afinidade epistemológica com a idéia aqui apresentada do trabalho em equipe da saúde mental como trabalho político. Pretendemos, com isto, uma aproximação que exponha a integralidade do cuidado, segundo Pinheiro (2001), na perspectiva da interação entre os trabalhadores de saúde.

A base empírica de nossa discussão se situa em uma pesquisa realizada em 2006, com o objetivo de pensar o trabalho da equipe de saúde mental responsável pelos serviços residenciais terapêuticos do município de Carmo, no Estado do Rio de Janeiro. Propomos abordar os aspectos mais relevantes que a pesquisa revelou, basicamente em relação a algumas interações entre os moradores e a sociedade civil, e sobre o trabalho direto com o morador. Corresponde, portanto, às percepções dos profissionais sobre como conduzem seu trabalho neste universo social, revelando suas visões sobre a forma como está se dando a interação social e sobre seu papel no processo.

\section{O trabalho humano como práxis}

As análises do processo de trabalho desenvolvidas pela ergologia e pela psicodinâmica do trabalho francesas referem-se a um campo múltiplo, que procura pensar em diferentes abordagens a relação entre trabalho e saúde. 
A Ergonomia é uma disciplina que procura adaptar o trabalho às pessoas, cujo marco teórico, segundo Vieira (2004), foi dado por Leplat e Hoc, com a diferenciação entre tarefa e atividade. Pois entre a tarefa prescrita e a tarefa executada ocorre uma defasagem, um processo de renormalização, no qual o social se encontra radicalmente implicado.

Central a estas disciplinas é o conceito marxista do processo de trabalho, que o analisa numa dimensão histórica e social. Este modelo parte de uma concepção diferenciada de homem, entendendo o trabalho como práxis que produz a natureza e também a própria subjetividade humana. $\mathrm{O}$ materialismo histórico só entende a natureza como um produto do trabalho do homem. O homem é produto da natureza, ao mesmo tempo em que a produz. É, portanto, o trabalho que torna o homem "verdadeiramente humano", pois, "atuando assim sobre a natureza externa e modificando-a, ao mesmo tempo modifica sua própria natureza" (MARX, 2002, p. 211).

Segundo Muniz (2000), Leplat vê a tarefa como contrainte (pressão, algo que constrange) para o operador, e a atividade como algo que transforma a tarefa e o próprio operador. Para realizar a tarefa, o operador se depara com diversas fontes de variabilidades. Em síntese, a prescrição é redefinida devido à variabilidade do mundo.

A psicodinâmica do trabalho de Dejours (2004) entende que toda atividade de trabalho é regulada pela interação entre pessoas, na qual destaca o aspecto da confiança, que suspende as relações de força no trabalho. A tarefa demanda uma integralidade que não se realiza somente no indivíduo, mas na interação entre os membros da equipe. Só a publicização (ou, como diria Arendt, a exposição no espaço público) divide as responsabilidades e insere a tricherie, o "macete" individual, na tradição, reconhecendo-o como ato técnico. E é a confiança entre as pessoas que torna possível a visibilidade, constituindo o pré-requisito para a realização deste espaço público no trabalho. A confiança é garantia dessa integralidade, e se fundamenta em competências éticas - "diz respeito à eqüidade dos julgamentos pronunciados pelo outro sobre a conduta do ego, no triângulo dinâmico do trabalho" (DEJOURS, 2002, p. 53).

Dejours pressupõe que, para além do conceito de atividade, a análise da atividade coletiva do trabalho deve ser abordada através da teoria da ação (práxis), pois inclui uma atividade de construção de normas e valores. 
Em termos mais teóricos, somos assim conduzidos a admitir que o trabalho não pode ser apreendido somente pelas categorias clássicas da produção (poiesis). Ele implica também categorias teóricas da ação (praxis), onde todos os elos intermediários (visibilidade, confiança, julgamento, reconhecimento, arbitragem, discussão, racionalidade comunicativa) são as categorias extraídas da "teoria da ação" (DEJOURS, 2002, p. 61).

Uma tal epistemologia da ação, que focalize a relação do homem com o mundo na ação, deve, portanto, incluir a subjetividade ao pensar a verdade. Avaliar o fator humano no trabalho é, para Dejours, avaliar a qualidade da cooperação nas interações subjetivas dos coletivos de trabalho.

A partir de uma crítica ao modelo taylorista de trabalho, a Ergologia surgiu na França, na década de 80 , através de um coletivo pluridisciplinar de formação. Inspirada por idéias de Canguilhem, da ergonomia situada e da comunidade alargada de pesquisa de Oddone, na Itália, a Ergologia propõe um novo modo de produção de conhecimento, caracterizado pela inter-relação entre as disciplinas e pela participação dos trabalhadores na elaboração do saber (MUNIZ, 2000; BRITO, 2004).

Coerente com a concepção de Canguilhem (2006) sobre os seres vivos serem capazes de produzir modos de vida ante a infidelidade do meio, Schwartz (2006) destaca o caráter industrioso do homem que o taylorismo, ao pretender o trabalho como a repetição invariável das tarefas, desconsiderava.

A renormalização da atividade singulariza a experiência de trabalho, é fruto desta atividade industriosa que ultrapassa o domínio de disciplinas específicas. Yves Schwartz (2006) valoriza a experiência como fonte para a compreensão das situações de trabalho, em uma relação dialética com o conhecimento científico. Propõe um modelo de produção de conhecimento, o dispositivo de três pólos, que articule as contribuições das diferentes disciplinas (pólo dos conceitos), os saberes e valores dos trabalhadores, gerados nas atividades (pólo das forças de convocação e reconvocação), e por fim o pólo das exigências éticas e epistemológicas, que faz a liga do modelo.

Os saberes produzidos no segundo pólo convocam as disciplinas a pensar a experiência de trabalho (as forças de convocação), que acabam por transformar a própria disciplina, reconvocando-a. Mas o terceiro pólo é o operador do sistema, pois postula uma ética para as relações de parceria, pautada por valores de uma 
filosofia da humanidade que exigem uma posição de humildade e respeito ante o conhecimento do outro.

O conceito de normas antecedentes permite a Schwartz (2006) ver o trabalho como atividade industriosa, como um debate de normas (e, portanto, uma política) que, embora presentes no ambiente de trabalho, ultrapassam este ambiente. As normas antecedentes são construções históricas heterodeterminadas e indicam valores de bem comum, redimensionados, institucionalizados no ambiente de trabalho. Para Schwartz (2004), os valores de bem comum (ex: saúde) são valores não dimensionados, difundidos na vida social e que se corporificam como valores dos protagonistas da atividade industriosa, ou se tornam valores dimensionados nas normas antecedentes. Segundo Tellez e Alvarez (2004, p. 74), "esses valores são objetos de debates, de conflitos, de arbitragens políticas. De certa maneira, são valores que transcendem como idéias reguladoras as conjunturas nas quais vão operar, mas que devem funcionar em princípios de ação em todas as circunstâncias”. Os valores, portanto, orientam as escolhas, mas podem estar também dimensionados na prescrição.

Para Schwartz (2004, 2006), mesmo em uma administração taylorista de trabalho, os operadores transformam as prescriçōes para atingir outros objetivos, como a produtividade e a economia corporal. A atividade é lugar das dramáticas do uso de si, lugar de tensão problemática onde, mesmo que não aparentemente, o indivíduo em seu ser é convocado.

Há uma dialética entre o uso de si pelos outros, que inclui as normas e limitações que heterodeterminam o sujeito, e o uso de si por si, onde o sujeito busca escapar das contraintes que caracterizam o real do trabalho, constituindo as renormalizações.

O setor de serviços, como o setor saúde, que tem como objeto de trabalho outros seres humanos, torna mais complexa a avaliação da competência do trabalhador, dada a dimensão relacional da atividade. Cada usuário, dependendo dos objetivos que o profissional deseja alcançar na atividade, delimita um determinado horizonte de uso, que guia um repertório de ações. Por exemplo, dependendo de como os trabalhadores de saúde entendem o cuidado, cada qual elabora um cardápio específico de usos de si.

Dejours (2002) já ressalta que a noção de competência não deve ser naturalizada, pois depende de um contexto ético e social, sendo coletiva, antes de ser individual. Mas para Schwartz (1997), a competência envolve diversos “ingredientes” que 
podem ser avaliados separadamente, e que vão desde a repetição de um protocolo, até a consideração da chamada qualidade sinérgica, produto da interação das diversas sinergias, o que é mais do que a soma dos desempenhos individuais, na medida em que as competências individuais se transformam na negociação com as outras. Mas esta qualidade também depende de condições que possibilitem seu desenvolvimento.

\section{Metodologia}

Operamos a construção do plano de análise da pesquisa que embasa a discussão deste artigo a partir dos conceitos da ergonomia, de trabalho prescrito, trabalho real e renormalização. Esta pesquisa teve como universo de investigação as residências terapêuticas do município do Carmo (região serrana do Estado do Rio de Janeiro), cuja equipe profissional acompanhamos. Essas residências constituem uma etapa do processo de desinstitucionalização de um hospital psiquiátrico estadual do tipo colônia agrícola, o Hospital Estadual Teixeira Brandão (HETB), fundado na década de 40 do século passado, onde estavam internados cerca de 280 pacientes.

Os serviços residenciais terapêuticos $(\mathrm{SRTs})^{2}$ são dispositivos de assistência em saúde mental que estão diretamente no espaço da urbe. Foram concebidos principalmente para dar conta da questão do morar, fundamental quando se considera o contingente de pessoas afastadas de seu meio social pela internação psiquiátrica prolongada, e que perderam seus laços com famílias e comunidades de origem. Constituem dispositivos híbridos, pois são casas, moradias, mas são também tecnologias de saúde.

A partir de 2003, com o descredenciamento da unidade do sistema hospitalar do SUS pelo PNASH (Programa Nacional de Avaliação de Hospitais), a extinção do hospital é planejada e coordenada pelo gestor estadual - através de sua Assessoria de Saúde Mental (ASM), já que se tratava de uma unidade pública estadual. Através das açôes clínicas, uma parcela dos internos (cerca de 90) retornou ao seio familiar, mas a maioria foi alocada em residências terapêuticas, espalhadas pelas áreas urbana e rural do município. No momento de nossa pesquisa, o número de serviços residenciais terapêuticos do município de Carmo somava 29 casas, onde moravam 153 ex-internos. Dezessete delas encontravam-se na área urbana (o núcleo urbano), e 12 na área do antigo HETB, o núcleo rural.

Entendemos que observar este cenário revelaria os modos de fazer empregados nesse momento do processo de desinstitucionalização, um momento ainda inicial 
da interação com a sociedade civil, um momento de forças instituintes e de formação de atores. Mantivemos, portanto, a observação direta dos espaços de reunião dos técnicos, que, por si, são concebidos como espaços de análise. Nestes espaços, assim como nas abordagens individuais, interessava-nos tudo o que emergia como prioridade para a discussão pelos técnicos, entendendo que constituíssem naquele momento seus pontos de atravessamento e impasses, mas também o que surgia como avaliação e pudesse mostrar valores concernentes à tarefa e à sua realização. As situações de trabalho, sempre singulares, comportam um sentido para cada trabalhador, que procuramos também apreender, pois este sentido se relaciona com a implicação e muitas vezes condiciona as escolhas que ele realiza no dia-a-dia.

Em sua tese de doutorado sobre uma pesquisa-intervenção na área de saúde do trabalhador, na qual utilizou o referencial teórico-metodológico da ergonomia e da clínica da atividade, Osório (2002, p. 59) adverte: "deve ser analisado o que se faz, o que não se faz, o que se faz para evitar fazer alguma coisa, o que não se pode fazer e o que se gostaria de fazer".

Durante três meses freqüentamos, por dois dias consecutivos na semana, o município de Carmo e seu programa de residências terapêuticas. Durante o primeiro mês, acompanhamos as coordenadoras do programa; no segundo mês, uma técnica da referência (profissional de nível superior, responsável pelo cuidado de três a quatro casas), e no terceiro, uma residência específica. Isto nos possibilitou uma aproximação gradativa a um espaço mais íntimo, mais privado do cuidado, no qual interessava observar a dinâmica dos agentes entre si, com a rede e com o objeto de cuidado - os moradores.

Realizamos ainda uma oficina com um grupo de cuidadores, com a proposta de que pensassem seus impasses no trabalho (as contraintes), e uma entrevista com um cuidador, escolhido após indicação e observação, na qual procuramos abordar mais especificamente a gestão de seu processo de trabalho.

Poderíamos dizer que a atividade de referência que nos permitiu uma modelagem mais aprofundada do processo de trabalho coletivo nas residências terapêuticas de Carmo foi a atividade da "Casa Vermelha" e, mais especificamente, as atividades de um determinado cuidador. Mas consideramos também que as observações das atividades dos demais profissionais desta residência (outros cuidadores e técnica de referência) e as atividades dos demais técnicos de referência e das coordenadoras do programa de residências terapêuticas de Carmo eram igualmente importantes, 
no sentido de permitirem incluir e considerar a atividade deste cuidador como parte de uma atividade coletiva. Outro espaço importante foram os ambientes sociais, onde pudemos observar também a inter-relação entre os usuários, profissionais e membros da sociedade civil. O resultado final foi então um mapeamento, uma cartografia (BARROS,1994, p. 179) do atual estado da arte do trabalho da equipe responsável pelo cuidado aos moradores dos serviços residenciais terapêuticos de Carmo.

A observação do ambiente social da cidade do Carmo, embora não houvesse sido selecionada como estratégia metodológica, ofereceu material fértil para a análise do trabalho da equipe e das interaçôes profissionais - moradores - sociedade civil, incluídos em alguns pontos de reflexão.

Esta pesquisa foi aprovada pelo Comitê de Ética em Pesquisa do Instituto de Medicina Social da UERJ em 16 de agosto de 2006.

\section{Discussão dos resultados}

Durante a pesquisa, as noites na praça central da cidade nos permitiram observar que, nestas ocasiōes de convívio social, vários agenciamentos objetivos são feitos pela equipe: da comunicação de informes à discussão de casos, estabelecimento de novas estratégias, pactuações e encaminhamentos.

Em uma cidade pequena como Carmo, é interessante ver como a equipe técnica convive e realiza nesses espaços, em princípio considerados privados, seu projeto de trabalho. Ir ao forró é também conviver com M., morador que passa os dias e noites em pé na praça, tudo observando, e convidá-lo a sentar à nossa mesa. É discutir a internação de um paciente com uma de suas referências informais, o dono de restaurante onde vamos comer. E poder perceber, na interação com a sociedade civil, que estatutos vão sendo colocados em jogo, no tecido social, para o portador de transtorno mental, para os ex-pacientes do HETB.

\section{Interações com a sociedade civil}

Em reunião, a técnica de referência C. diz estar bastante irritada, pois um profissional liberal da cidade havia realizado, sem consultá-la, um procedimento claramente desnecessário em um morador (Diário de Campo, 26/07/2006). 
Poucas semanas depois, C. conta em reunião que "finalmente esfriou a cabeça" e foi procurar o profissional. Ele alegou que foi o morador quem pediu que ele realizasse o procedimento. Ela diz ao profissional que D. "não responde por si mesmo", e que portanto ele não deveria ter realizado o procedimento sem o consentimento dela (Diário de Campo, 17/08/2006).

O episódio acima ilustra as tensões entre a equipe e o profissional liberal contratado, caracterizando uma situação em que prevalece uma oposição de interesses. Ao mesmo tempo percebe-se, na postura da técnica de referência, a necessidade de afirmar, junto à sociedade civil, uma tutela (SILVA, 2004). Ela precisou marcar uma instância social de responsabilidade pelo morador, e incorporála em si. A nosso ver, o trabalho cotidiano revela como na relação com a sociedade é muitas vezes o louco quem deve ser protegido.

Serve, ainda, para uma medida das negociações de si (SCHWARTZ, 2006) que a técnica de referência tem que realizar para se manter na tarefa. Para de novo procurar o profissional e esclarecer o que precisava ser esclarecido, a técnica precisou de "um tempo" para afastar do campo os afetos, o emocional excedente que a conduta do profissional mobilizara. Desta forma, a negociação com ele pode manterse num nível "diplomático".

Mas é através desses representantes - o médico da rede, o atendente do mercado, o caixa do banco - que outros modos de inserção podem ser ensaiados e experimentados. Assim, o cuidador identifica uma nova qualificação na relação entre o morador e os empregados do mercado:

A relação deles [os moradores] com a sociedade... É boa também [...] pessoal do mercado... [...] todo mundo teme o desconhecido... Então a pessoa não conhece, a pessoa, não sabe como é que é... Tem aquela fama de Teixeira [o HETB]... Ah, é hospital de maluco, então todo mundo que tá lá dentro vai chegar de uma hora pra outra e vai dar um soco na cara de um... E não é bem assim, entendeu? Então tem aqueles que ficam com medo, mas tem outros que depois que conhecem, passam a conversar... Conversam bem... Procuram, passam lá... Tem um pessoal do mercado que passa em frente da casa, pára prá conversar com o F., pára pra conversar com B... F. vai lá no mercado, conversa com eles [...] (entrevista com cuidador).

Nada mais explícito do que o investimento do cuidador e a crença, a partir da experiência, em uma possibilidade de mudança da sociedade civil que se dá pela via da comunicação e da convivência. 
Um dos fatores que sustentam a inserção social dos ex-pacientes do HETB em Carmo é seu empoderamento como consumidores dos bens produzidos, a começar pelo impacto na área imobiliária, com o grande número de casas alugadas. Depois, pelo quantitativo de mão-de-obra que emprega, na função de cuidadores. Por último, mas não menos importante, os próprios moradores e os benefícios financeiros que recebem (como a bolsa-auxílio do Programa de Volta pra Casa, do governo federal, para pacientes desinstitucionalizados, e que pode ser acumulada com um benefício do LOAS ou do INSS, por exemplo).

De fato, é enorme o volume de capital que o projeto coloca em circulação. Alguns indicadores: no início do projeto, era difícil conseguir proprietários que se dispusessem a alugar os imóveis para a prefeitura; atualmente, os gestores são procurados pelos proprietários que oferecem os imóveis. Outro: o relato de que os moradores têm crédito liberado no comércio local, face à estabilidade de sua renda. Lojas de eletrodomésticos, vendedores de seguro, taxistas: através das relações comerciais se dá uma boa parte do trabalho de inserção social. O consumo é, assim, oportunidade para o relacionamento.

A visão preconceituosa do louco agressivo é aos poucos matizada por novas experiências. Em verdade, o que parece garantir uma certa tranqüilidade da população civil é o aparato técnico que cerca o projeto. A presença constante de cuidadores nos serviços residenciais garante um acesso rápido em caso de problemas. Há sempre um empenho da equipe e dos coordenadores em responder às solicitações ou queixas da sociedade civil, e eles entendem que o sucesso do projeto depende de uma boa relação entre seus membros e os moradores. Assim, a agressividade e os distúrbios graves de conduta tendem a ser contidos, e são respondidos o mais rapidamente possível, seja pela internação no hospital geral ou no hospital psiquiátrico conveniado (em Friburgo). Estes sintomas são também tomados como indicador de uma má adaptação do morador à casa, podendo sugerir uma mudança de residência, ou, em alguns casos, ser tomados como inadaptabilidade do morador à vida na cidade, gerando um retorno ao núcleo rural. Assim, um morador mudouse para uma área mais calma da cidade, pois em uma rua mais movimentada ele se excitava com freqüência, com a grande quantidade de carros e cachorros que passavam, e invadia as casas dos vizinhos para queixar-se.

Todos os técnicos são bastante atentos e cuidadosos na mediação entre os moradores e a sociedade civil. 


\begin{abstract}
Em reunião na varanda da casa, sentam-se moradores, cuidadores e técnica de referência. Um dos moradores, um negro alto de cerca de 50 anos, vestindo shorts, acocora-se no chão e encosta as costas na parede. A técnica, observando que ele está em frente ao portão, vai até ele e diz: "Deixa eu ver se tem alguma coisa aparecendo... Pode passar uma criança na rua...” E constatando a exposição genital involuntária, convida-o a sentar-se em outro lugar. Ele atende-a imediatamente (Diário de Campo, 17/08/2006).
\end{abstract}

\title{
Intervençōes junto ao morador: "técnicas" da atividade
}

Iremos nos deter agora na natureza de algumas intervenções técnicas que os profissionais realizam junto aos moradores das residências terapêuticas. Este trabalho só é possível quando há um vínculo de confiança entre cuidador e objeto de cuidado. Os cuidadores investem na construção e manutenção deste vínculo e por vezes o chamam "amizade".

Em sua dissertação de mestrado, Araújo (2006) postula que esta amizade que caracteriza o plano da clínica não se confunde com um reconhecimento do mesmo. Assim, em um caso em que havia grande vinculação entre o morador e o cuidador, houve um momento em que a estratégia foi que o cuidador deixasse o morador sozinho no Centro de Atenção Psicossocial (Caps), para que ele pudesse descolar-se um pouco, diferenciar-se do amigo para estabelecer novos vínculos. Neste mesmo sentido, Ortega (2000) reporta-se a Arendt e trata a amizade como fenômeno político, que se dirige à pluralidade e à distância necessária à manutenção de um mundo compartilhado, diferente da fraternidade, que aspira à mitologia familiar e à indiferenciação.

Há uma série de procedimentos que constroem o saber-fazer dos cuidadores: o jeito de corpo que o trabalhador desenvolve para realizar a tarefa. Identificamos no trabalho dos serviços residenciais terapêuticos de Carmo um repertório de ações que os profissionais utilizam de acordo com as situaçôes e que configuram uma técnica pessoal, enriquecida e posta em ação na experiência cotidiana. Como explica Dejours (2002), a técnica é ação sobre o mundo que transforma o homem no ato do trabalho, integrando um corpo, um raciocínio e uma cultura.

Nesta explanação, tomaremos por base tanto nossas observações do campo, como, especialmente, o depoimento de um cuidador, rapaz natural de Carmo, que não trabalhava em saúde anteriormente. De início, é preciso caracterizar como ele define sua tarefa, o objetivo principal de seu trabalho. 
Penso que é tentar recuperar ao máximo a vida dessas pessoas que foram internadas esse tempo todo e que perderam a noção de convivência dentro do centro urbano - acho que quase todos, né? - mas eu queria que o pouco tempo que eles têm de vida, ou muito tempo, que a gente não sabe, seja melhor do que estava sendo dentro do hospital (entrevista com cuidador).

A tarefa, como ele a entende: ele já parte de um valor, de que o manicômio isola, que o morador estava em situação de desvantagem, de sofrimento. Sua função é reparadora, é de reabilitar. Há um risco aí, o de determinar o que é melhor para o outro. Mas ele se sustenta por suas premissas, que são éticas e se afirmam numa cultura antimanicomial.

Em seu trabalho com os moradores, a pesquisa revela um repertório de ações que, no dia-a-dia, giram em torno de determinados temas: o uso do dinheiro (cujo manejo e prestação de contas, problemático para a clientela dos moradores desinstitucionalizados, ocupa um volume considerável de tempo dos técnicos); o estímulo e trabalho das relações interpessoais, principalmente a convivência entre os moradores de cada residência; os elementos e hábitos do processo civilizatório, como o uso de talheres à mesa, e o cuidado com os hábitos higiênicos, como o uso adequado do banheiro para as atividades fisiológicas; a apropriação do espaço da casa e a responsabilização dos moradores por este espaço coletivo.

Há, ainda, uma série de recursos que os profissionais utilizam, na relação com os moradores, com o objetivo de estimular o uso do pensamento. O cuidador estimula, induz o morador à comunicação, e a oportunidade para isto se dá na necessidade de resolver problemas; questôes que a vida nos coloca, desafios e obstáculos que devemos enfrentar. Com este objetivo em mente, o cuidador tende a "estranhar" coisas que, por vezes, são tomadas como naturais, como verdades finais. Daí sua preocupação de não responder, de problematizar com o morador.

O saber-fazer é constituído nessas apostas clínicas, em processos de questionamentos, erros e acertos que configuram uma técnica para os profissionais, uma técnica nunca automatizada. Abordando a questão do risco na atividade humana, Nouroudine (2004) postula que, durante o processo de renormalização das situaçôes de trabalho, a infração em relação às normas antecedentes é condição necessária à construção dos saberes-fazeres de prudência, úteis para a eficácia e para a saúde no trabalho. Assim, o correr risco ganha positividade na atividade humana. 
As indagações dirigidas ao morador buscam, em muitas ocasiōes, encontrar o sentido para as atitudes, como quando se investigam as hipóteses causais para as crises e desestabilizações. Nesses momentos, a dimensão coletiva é convocada em sua potência, e os profissionais se alternam para suportar a relação conflitiva com o morador.

É um trabalho onde se impõe a necessidade de lidar com o imprevisível e, muitas vezes, o sem sentido inerente aos eventos humanos; com o que não se consegue entender, nem mudar, e que causa frustração. Esta experiência com a resistência, própria dos relacionamentos humanos e muitas vezes radicalizada no trabalho com os portadores de transtorno mental, corporifica o real do trabalho de Dejours (2002), o que escapa ao conhecimento técnico-científico e instiga à investigação, e é apreendido como experiência. Real como substantivo, diferente da realidade como um estado de coisas. No trabalho, é o real que induz, necessariamente, a um reajuste, pelo operador, dos objetivos e da técnica.

Embora planejado em projetos terapêuticos individualizados, o trabalho com os moradores não pode ter, em sua execução, um planejamento detalhado. A reinserção social depende da vida cotidiana na cidade, no que se apresenta como oportunidade, na qual a atenção e a curiosidade do profissional procuram brechas.

Paciência e perseverança parecem ser outros requisitos para o cuidador, que afirma em entrevista: o "o meu trabalho é um trabalho de formiga", destacando a lentidão das respostas dos moradores e a necessidade de um esforço conjunto e de uma crença na proposta.

Lidar com as diferenças é o desafio dos relacionamentos sociais. O cuidador medeia a interação morador-sociedade no espaço público. A convivência social impõe limites e o aparo de arestas. A atividade política é esse exercício de negociações, de argumentaçôes e debates, que constituem o espaço público. A técnica do trabalho político do cuidador utiliza essas ferramentas em seu cotidiano. Circular no espaço social exige a aquisição de determinado universo simbólico que possui suas normas. É preciso observar regras de comportamento e de civilidade, sobretudo aprender também a respeitar o outro. O convencimento é fruto de uma relação de argumentação que se dirige a um outro posicionado que pretendemos cuidadosamente mover.

O banho lá na residência tá difícil... Eu queria que o B. tomasse banho, mas ele não toma, não. Então tem coisas que você tem que descobrir o que vai funcionar. Tem dias que é banho de descarrego, tem dias que é banho de cachoeira... A S. 
(cuidadora) no outro dia conseguiu que ele tomasse banho. Ela simplesmente falou pra ele: cheira seu braço. Ele pegou, cheirou. Ela falou: Está cheirando bem? Ele falou: não. Ela então falou: tem que tomar um banho. Aí ele foi, tomou. Deu certo: dois, três, quatro dias, deu certo. Depois parou de novo. A gente agora tá tentando descobrir uma outra coisa (entrevista com cuidador).

O cuidador toma o fracasso como desafio para a criação, para a tentativa. A atividade é eminentemente política, no sentido do convencimento, da argumentação que se dá no trabalho vivo, no encontro com o morador.

O cuidador questiona a rigidez de horários no Caps para o início e fim das atividades: diz que acha que são as oficinas que têm que se adaptar ao usuário e não o usuário à oficina. A técnica de referência estimula-o a expor suas idéias no Caps. O cuidador explica que os moradores "têm o tempo deles", e que é difícil muitas vezes arrumá-los de manhã para sair. Então chegam atrasados. Diz que tem dias em que a casa está uma confusão pela manhã e eles estão muito agitados; mas de tarde pode ser que eles estejam tranqüilos (Diário de Campo, 17/08/2006).

Com efeito, para que sejam aceitas e executadas pelos moradores, as tarefas têm que ser negociadas, uma relação diferente do tempo do asilo, onde as atividades de tomar banho, comer, tomar remédio, da forma como eram impostas, num dispositivo de regularização e de homogeneização, não levavam em conta a relação diferenciada. Reorganizar o sentido dessas ações para cada morador é uma tarefa política e precisa preservar o tempo dos diálogos. A tarefa de levá-los ao Caps deve necessariamente ser renormalizada na atividade, já que o que importa para o trabalho terapêutico não é o fato de eles irem ao Caps, mas de como eles vão ao Caps e aproveitam o dispositivo.

A negociação política da atividade junto ao morador leva o cuidador a realizar uma outra ação política, forçando-o a empreender a ação de negociar e colocar em análise o dispositivo Caps. Como observa Schwartz (1998), a questão do tempo não se reduz ao tempo de mercado (o tempo do relógio): há ainda o tempo ergológico (o tempo da atividade, que inclui a renormalização) e o tempo da política (dos valores do bem comum). Assim, para dar conta do que se propõe, o dispositivo Caps deve negociar o horário estabelecido das atividades com o tempo de uma política de desinstitucionalização, tempo para a reinserção social, e com o tempo da atividade que leva em conta o outro em sua diferença e especificidade. 
Quando eu acho que um deles está meio diferente, eu chego, pergunto. A gente chega, pergunta o que tá acontecendo... Tem uns que [...]. O F., quando ele está meio quietão, meio assim, não adianta perguntar nada, ele vai ficar só te olhando, balançando a cabeça, não vai falar nada. O P., você pergunta, ele não fala não: "ah, quero lá saber de nada!?” Aí deita. Depois, ele vai, senta, e fala. Você pergunta: "por que você estava daquele jeito, não sei o quê?" Ele pega e fala: "não, foi fulano que fica ali, não sei o quê" [...]. Hoje ele ia ao dentista, ele e o R. A A. [técnica de referência] me ligou, pra falar do dentista, aí eu falei com ela: "vai o P. e o R.. Aí o R. falou:”eu vou no dentista?”. Aí eu respondi que sim. O P. estava perto do telefone e daí pra cá ele já ficou quieto. Ficou rodando de um lado pro outro, não falou mais nada, ficou emburrado [...]. Aí a S. [cuidadora] falou assim:"pode ser por causa do dentista". E eu falei assim: "ah, então eu vou ficar aqui, deixa ele aí... Você leva o R". Pois na hora que ela e R. chegaram ele levantou. Aí ela foi conversar: "ué, seu P., por que o senhor estava quieto até agora?" E ele: "Não, não quero ir ao dentista não, esse negócio de dentista dói meu dente!”. Devem ter arrancado o dente dele lá na Colônia errado, alguma coisa errada que doeu o dente dele (Diário de Campo, 04/10/2006).

Os cuidadores intuem a razão do amuo do morador; pois eles buscam entender a coerência, a significação na atitude dos moradores. A partir disto, eles arriscam e não o levam ao dentista. A tarefa sofre renormalização. Ela não é executada em função de algo mais importante, que ganha prioridade naquele dia, a singularidade do morador e seu arbítrio em relação às decisões.

Esse saber-fazer, metis que é forjado na experiência, caracteriza a inteligência astuciosa de Dejours. Está enraizada numa espécie de mimetismo corporal, é criativa e prioriza a habilidade em detrimento da força.

A astúcia, essencialmente fundamentada na mobilização subjetiva, passa pela familiarização com o processo de trabalho, por colocar em ressonância o corpo com a matéria ou a máquina e por um certo "mimetismo" que permite antecipar e intuir os acontecimentos que poderão produzir-se graças ao jogo de uma sensibilidade intencional (DEJOURS, 2002, p. 50).

\section{Conclusões}

Ao permitir uma abordagem pormenorizada dos processos de trabalho, por pensálos como flexibilização necessária e criativa das normas, a aplicação de ferramentas da análise ergológica nos permitiu uma análise do trabalho da equipe de saúde mental duplamente produtiva: por um lado, colocou em análise a atividade dos 
profissionais, estimulando uma reflexão sobre as ações; por outro, revela os novos atores que conduzem o processo de desinstitucionalização na porosidade da vida cotidiana das cidades.

O trabalho clínico do profissional de saúde mental é também um trabalho político, no sentido arendtiano, já que cuidar é estimular negociações que permitam uma ampliação da normatividade (conceito derivado de Canguilhem). A própria constituição da equipe multiprofissional é um modo político de articulação, no qual os sujeitos e seus saberes interagem e se transversalizam.

No trabalho de acompanhamento às residências terapêuticas de Carmo, os profissionais dão vida à própria política de saúde mental, constituindo-se como atores de uma ação integral, que promove cuidado e autonomia, e confere direitos de cidadania. A integralidade é, portanto, atividade coletiva e social. Integrar é fazer rede, é ampliar, é chamar outros a agir. É, então, fazer valer uma política das relações.

A experiência dos técnicos produz uma técnica de escuta e mobilização em constante movimento. O trabalho sustenta-se no encontro das diferenças. É no escopo do mundo comum da pluralidade que a tarefa política da reforma Psiquiátrica Brasileira ganha sentido.

A realização da tarefa requer lentidão e perseverança e a constituição de uma equipe (rede). A realização das tarefas depende de renormalizações e negociações. O trabalho é práxis política, que visa à transformação social e produz subjetividade ao profissional. Na equipe, destaca-se o papel dos cuidadores como novos intelectuais da Reforma, em ação no ambiente social. Em seu trabalho cotidiano com os moradores, eles se corporificam como multiplicadores sociais da proposta.

O trabalho relatado é a etapa de um processo que se sustenta, ainda, pela vontade política dos gestores e técnicos que circulam em um cenário heterogêneo: em toda a sua plenitude, o projeto aspira ainda à hegemonia social.

\section{Referências}

ARAÚJO, F. Um passeio esquizo pelo acompanhamento terapêutico: dos especialismos à política da amizade. Niterói: Fábio Araújo, 2006.

ARENDT, H. A condição humana. Rio de Janeiro: Forense Universitária, 1991.

. O que épolítica? Rio de Janeiro: Bertrand Brasil, 2004.

BARROS, R. D. B. de Grupo: a afirmação de um simulacro. São Paulo, 1994. Tese (Doutorado em Psicologia) - Faculdade de Psicologia, Pontifícia Universidade Católica, São Paulo, 1994. 
BOBBIO, N. Estado, governo e sociedade: para uma teoria geral da política. Rio de Janeiro: Paz e Terra, 2004.

BRASIL. Ministério da Saúde. Secretaria de Atenção à Saúde. DAPE. Coordenação Nacional de Saúde Mental. Reforma Psiquiátrica e Política de Saúde Mental no Brasil. Documento apresentado à Conferência Regional de Reforma dos Serviços de Saúde Mental: 15 anos depois de Caracas. OPAS. Brasília, novembro 2005.

BRITO, J. Saúde do trabalhador: reflexões a partir da abordagem ergológica. In: FIGUEIREDO, M. et al. (Orgs.). Labirintos do Trabalho: interrogaçōes e olhares sobre o trabalho vivo. Rio de Janeiro: DP\&A, 2004.

CANGUILHEM, G. O normal e o patológico. Rio de Janeiro: Forense Universitária, 2006.

DEJOURS, C. O Fator humano. Rio de Janeiro: FGV, 2002.

GRAMSCI, A. Cadernos do cárcere. V. 2. Rio de Janeiro: Civilização Brasileira, 2004.

HONORATO, C. E. de M. O Trabalho politico do profissional de saúde mental em um processo de desinstitucionalização: um estudo sobre integralidade e reforma psiquiátrica. Rio de Janeiro, 2007. Dissertação (Mestrado em Saúde Coletiva) - Instituto de Medicina Social, Universidade do Estado do Rio de Janeiro, 2007.

MARX, K. O capital: crítica de economia e política. V. 1, tomo 1. Rio de Janeiro: Civilização Brasileira, 2002.

MUNIZ, H. P. A gestão do tempo de permanência do paciente de neurocirurgia do Hospital Universitário Clementino Fraga Filho. Rio de Janeiro, 2000. Tese (Doutorado em Ciências em Engenharia de Produção) - Universidade Federal do Rio de Janeiro, 2000.

NOUROUDINE, A. Risco e atividade humana: acerca da possível positividade aí presente. In: FIGUEIREDO, M. et al. (Orgs.). Labirintos do trabalho: interrogações e olhares sobre o trabalho vivo. Rio de Janeiro: DP\&A, 2004. p. 37-62.

ORTEGA, F. Para uma politica da amizade: Arendt, Derrida, Foucault. Rio de Janeiro: Relume Dumará, 2000.

SILVA, C. O. da. Vida de hospital: a produção de uma metodologia para o desenvolvimento da saúde do profissional de saúde. Rio de Janeiro, 2002. Tese (Doutorado em Saúde do Trabalhador e Ecologia Humana) - Escola Nacional de Saúde Pública, Fundação Oswaldo Cruz, 2002.

PINHEIRO, R. As práticas do cotidiano na relação oferta e demanda dos serviços de saúde: um campo de estudo e construção da integralidade. In: PINHEIRO, R.; MATTOS, R. A. (Orgs). Os sentidos da integralidade na atenção e no cuidado à saúde. Rio de Janeiro: Abrasco, 2001. p. 67-113.

SCHWARTZ, Y. Les ingrédients de la compétence: un exercice nécessaire pour une question insoluble. Education Permanente, Paris, n. 133, p. 9-34, 1997. 
Concordance des temps? Le travail, le marché, le politique. Actes du colloque Le temps. Nantes, p. 5-16, mars 1998.

Trabalho e gestão: níveis, critérios, instâncias. In: FIGUEIREDO, M. et al. (Orgs.). Labirintos do trabalho: interrogações e olhares sobre o trabalho vivo. Rio de Janeiro: DP\&A, 2004. p 23-33.

Entrevista. Revista Trabalho, Educação e Saúde. Rio de Janeiro, v. 4, n. 2, set. 2006. Disponível em: www.revista.epsjv.fiocruz.br/revista . Acesso: 29 dez. 2006.

SILVA, M. B. B. e. Responsabilidade e Reforma Psiquiátrica brasileira: sobre a produção de engajamento, implicação e vínculo nas práticas de atenção psicossocial. Rio de Janeiro, 2004. Dissertação (Mestrado em Saúde Coletiva) - Instituto de Medicina Social, Universidade do Estado do Rio de Janeiro, 2004.

TELLES, A. L.; ALVAREZ, D. Interfaces ergonomia-ergologia: uma discussão sobre o trabalho prescrito e normas antecedentes, In: FIGUEIREDO, M. et al. (Orgs.). Labirintos do trabalho: interrogações e olhares sobre o trabalho vivo. Rio de Janeiro: DP\&A, 2004. p. 63-90.

VIEIRA, M. A. Autoconfrontação e análise da atividade. In: FIGUEIREDO, M. et al. (Orgs.). Labirintos do trabalho: interrogações e olhares sobre o trabalho vivo. Rio de Janeiro: DP\&A, 2004. p. 214-237.

\section{Notas}

${ }^{1}$ Pesquisa esta que subsidiou a dissertação de mestrado em Saúde Coletiva defendida no IMS-UERJ, em 2007: O trabalho político do profissional de saúde mental em um processo de desinstitucionalização (HONORATO, 2007).

${ }^{2}$ Serviços residenciais terapêuticos ou residências terapêuticas referem-se, neste artigo, à mesma modalidade de dispositivo. Usaremos qualquer um dos termos, indiscriminadamente, ou ainda as abreviaçōes SRTS ou RTS. Foram regulamentados pelas Portarias GM/MS nos 106/2000, 2.068/ 2004 e $1.220 / 2000$. 


\section{The work of the mental health professional in a deinstitutionalization process}

The article presents part of a research work carried out in 2006 on the work of mental health professionals who assist dwellers of residential care homes in the city of Carmo, State of Rio de Janeiro. These residences integrate the process of deinstitutionalization of a state Psychiatry Hospital, an agricultural colony, established in the 1940's, with about 280 inpatients. From 2003 on, when the hospital was closed by the state manager, and resources were municipalized, a small part of inpatients returned to their families, but the majority (153) were placed in care homes, scattered over country or urban district areas. Taking the task of social inclusiveness as the political bias of Brazilian Psychiatric Reform, the daily work of the multi-professional team is focused. In this relational work level, we chose the ergologic approach as a conceptual framework to analyze the work processes. It is a step in a process, still half way between state and municipal administration, where the proposal is sustained by the administrators' political will, and, in becoming hegemonic, must be discussed among professionals and the civil society. The landscape is not homogeneous, and the dynamics reveal the various understandings and interests. This article discusses how professionals work with civil society, being their goal the change of the mentally ill social status. The daily experience of the professionals who work closer to the residents, as the caretakers, produces a "technique" of listening and stimulation, which by no means admits unchangeable or pre-established rules.

> Key words: Deinstitutionalization; residential care homes; political work; integrality; Psychiatric Reform. 